\title{
Voltammetric characterisation of the self-assembled monolayers (SAMs) of benzyl- and dodecyl-mercapto tetra substituted metallophthalocyanines complexes
}

\author{
Bolade Agboola $^{\text {a, }}$, Philippe Westbroek ${ }^{b}$, Kenneth I. Ozoemena ${ }^{c}$ and Tebello \\ Nyokong ${ }^{\mathrm{a}}$
}

${ }^{\mathrm{a} C h e m i s t r y}$ Department, Rhodes University, Grahamstown 6140, South Africa

${ }^{\mathrm{b}}$ Department of Textiles, Ghent University, Technologiepark 907, B-9052 Gent, Belgium

${ }^{c}$ Chemistry Department, University of Pretoria, Pretoria 0002, South Africa

\begin{abstract}
Voltammetric characterisations of cobalt, iron, manganese, nickel and zinc phthalocyanine complexes tetra substituted with benzyl- and dodecyl-mercapto ring substituents and immobilisation on gold electrodes via the self-assembling technique are presented. The self-assembled films are stable and showed blocking characteristics towards the following Faradaic processes; gold surface oxidation, under potential deposition of copper and solution redox chemistry of $\left[\mathrm{Fe}\left(\mathrm{H}_{2} \mathrm{O}\right)_{6}^{3-1}\right]\left[\mathrm{Fe}\left(\mathrm{H}_{2} \mathrm{O}\right)_{6}^{2+}\right]$. The solution chemistry of $\left[\mathrm{Fe}(\mathrm{CN})_{6}\right]^{-3} /\left[\mathrm{Fe}(\mathrm{CN})_{6}\right]^{-4}$ redox process was used to study the orientation of the CoPcs-SAMs and this revealed a possible deviation from flat orientation of the complexes on the gold electrodes when the SAM formation times were greater than $24 \mathrm{~h}$. For SAM formation time at 24 and $48 \mathrm{~h}$, CoTDMPc-SAM showed more inhibition of the $\left[\mathrm{Fe}(\mathrm{CN})_{6}\right]^{-3} /\left[\mathrm{Fe}(\mathrm{CN})_{6}\right]^{-4}$ redox process than the CoTBMPc-SAM counterpart, indicating more blocking characteristics of the dodecylmercapto ring substituents compared to the benzylmercapto counterpart. To avoid SAM desorption, the potential application should be limited to -0.2 to $+0.8 \mathrm{~V}$ vs. $\mathrm{Ag} \mid \mathrm{AgCl}(\mathrm{NaCl}$, sat'd) in acidic and neutral $\mathrm{pH}$.
\end{abstract}




\section{Article Outline}

1. Introduction

2. Experimental

2.1. Materials and reagents

2.2. Apparatus and procedure

2.3. Procedure for electrode fabrication

3. Results and discussion

3.1. Optimisation of SAM formation time

3.2. Blocking characteristics of the faradaic reactions by MPc-SAMs

3.3. Central metal oxidation couples of the MPc-SAM electrodes

3.4. Stability of MPc-SAMs

4. Conclusion

Acknowledgements

References

\section{Introduction}

Metallophthalocyanines (MPcs) are well known to have vast numbers of applications because of their unique chemical and physical properties. Their applications in their early discovery was mainly as dyes but over the years, there have been many applications in areas such as, photovoltaic devices [1] and [2], molecular electronics [3], catalysis [4], [5], [6] and [7] and sensing [8].

In electrochemistry, chemically modified electrodes (CMEs) can be fabricated by using various techniques which include electropolymerisation [9], [10] and [11], dip-dry method [12], drop dry method [13], vapour deposition [14], [15] and [16], spin coating [17], Langmuir-Blodgett [18] and of recent self-assembled monolayer (SAM) technique. SAM technique is simple, reproducible and the molecules are chemically bound to the electrodes. Notable advantages of SAMs over other techniques for electrode modification are the high order and stability of the molecules on electrodes [19], [20] and [21]. The work on the use of thiol derivatised metallophthalocyanines to form SAMs on gold electrodes is still rather limited [15], [18], [22], [23] and [24] mainly due to the fact that 
the synthesis of thiol-derivatised metallophthalocyanines is tedious and requires toxic chemical reagents.

Long chain alkanethiols are known to form densely packed crystalline or liquid crystalline materials on gold with attractive Van der Waal forces between the alkyl chains which enhances the stability and order of the SAMs [25] but these SAMs are known to have short life span because with time the sulphur group gets oxidised due to exposure to the atmospheric oxygen. Thiol derivatised metallophthalocyanine SAMs have been shown to have their sulphur group protected by the phthalocyanine ring thereby increasing their stability [26]. Investigation of the influence of a long alkyl chain on the formation and stability of thiol derivatised metallophthalocyanine SAMs should therefore be of great interest. First row transition metal phthalocyanines complexes are well known to have excellent electrocatalytic behaviour and therefore the fabrication of first row transition metal MPcs-SAM for use as electrochemical catalysts and sensors should be of importance.

In this work, voltammetric methods are used to investigate the formation and integrity of SAMs of benzyl- and dodecyl-mercapto tetra substituted cobalt, iron, manganese, nickel and zinc phthalocyanines complexes (Fig. 1) on gold electrodes. The effects of the phthalocyanines ring substituents on the gold electrode coverage and the SAMs stability are investigated.

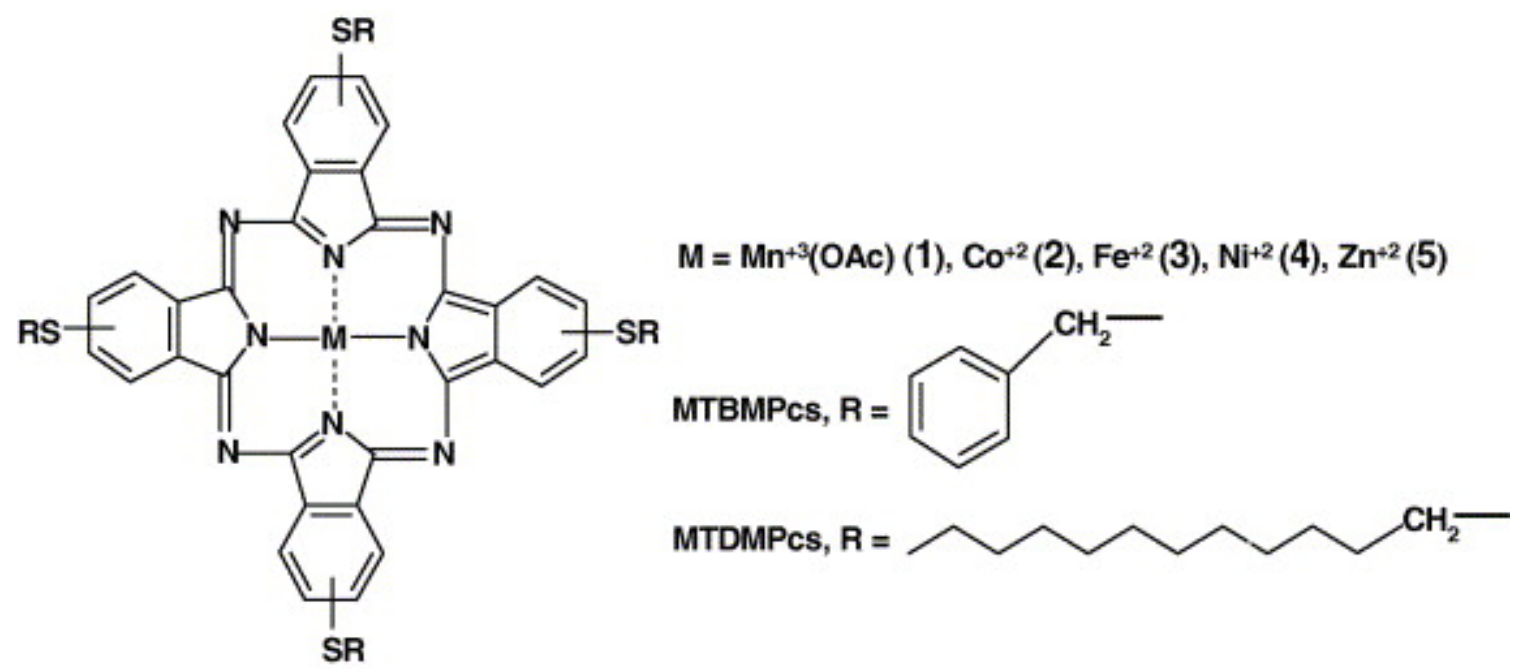

Fig. 1. General representation of the molecular structures of the metallophthalocyanine complexes. Tetrabenzyl mercapto phthalocyanine (MTBMPc) and tetradodecyl mercapto 
phthalocyanine (MTDMPc) complexes with $\mathrm{M}=\mathrm{Mn}^{+3}$ (1), $\mathrm{Co}^{+2}$ (2), $\mathrm{Fe}^{+2}$ (3), $\mathrm{Ni}^{+2}$ (4) and $\mathrm{Zn}^{+2}$ (5).

\section{Experimental}

\subsection{Materials and reagents}

The complexes, 1-5 (Fig. 1) were synthesised according to procedures recently reported [27]. All the reagents used for the synthesis of the complexes were of analytical grade and were used without further purification.

Dichloromethane (DCM, SAARCHEM) was distilled before use. When necessary, solutions used were deaerated by bubbling nitrogen prior to the experiments and the electrochemical cell was kept under nitrogen atmosphere throughout the experiments. Phosphate buffers were employed where needed.

\subsection{Apparatus and procedure}

SAM studies were carried out with the use of Advanced Electrochemical System (Princeton Applied Research) Parstat 2273 equipment with a three-electrode set-up consisting of either bare gold ( $r=0.8 \mathrm{~mm}$ from Bioanalytical systems, BAS) or MPcSAM modified gold electrodes, $\mathrm{Ag} \mid \mathrm{AgCl}(\mathrm{NaCl}$, sat'd) reference electrode and platinum wire counter electrode.

\subsection{Procedure for electrode fabrication}

The gold electrodes were polished with slurries of $1.0 \mu \mathrm{m}$ and $0.05 \mu \mathrm{m}$ alumina on a SiCemery paper (type 2400 grit) and then subjected to ultrasonic vibration in ethanol to remove residual alumina particles at the surface. The gold electrodes were then treated with 'Piranha' solution $\left\{1: 3(\mathrm{v} / \mathrm{v}) 30 \% \mathrm{H}_{2} \mathrm{O}_{2}\right.$ and concentrated $\left.\mathrm{H}_{2} \mathrm{SO}_{4}\right\}$ for about $1 \mathrm{~min}$, this step is necessary in order to remove organic contaminants and was followed by thorough rinsing with distilled water. The electrodes were then rinsed with ethanol and finally with dichloromethane (DCM). Following this pre-treatment, the electrodes were then placed in nitrogen-saturated $1 \mathrm{mM}$ solutions of the MPcs in DCM. After allowing the SAMs to form for a desired time, the modified electrodes were then thoroughly rinsed 
with DCM and dried gently in a weak flowing nitrogen gas. The modified electrodes were stored in nitrogen-saturated phosphate buffer $\mathrm{pH} 4.0$ at room temperature.

\section{Results and discussion}

\subsection{Optimisation of SAM formation time}

Prior to the SAM experiment, the real surface areas of the gold electrodes were determined using the conventional method, [20]. Using Randles-Sevcik equation

$$
I_{\mathrm{pa}}=\left(2.69 \times 10^{5}\right) n^{3 / 2} D^{1 / 2} v^{1 / 2} A C
$$

where $n$ is the number of electron transferred $(n=1), D$ is the diffusion coefficient of $\left[\mathrm{Fe}(\mathrm{CN})_{6}\right]^{-3}\left(7.6 \times 10^{-6} \mathrm{~cm}^{2} / \mathrm{s}\right), v$ is the scan rate $(0.05 \mathrm{~V} / \mathrm{s}), A$ is the geometric surface area $\left(0.0201 \mathrm{~cm}^{2}\right), C$ is the bulk concentration of $\left[\mathrm{Fe}(\mathrm{CN})_{6}\right]^{-3}(1 \mathrm{mM})$. The average surface roughness of the three-electrodes used in this work was found to be 1.05 (ratio of $I_{\text {pa experimental }} / I_{\text {pa theoretical }}$ ) corresponding to an average of $0.0211 \mathrm{~cm}^{2}$ (roughness factor $\times$ theoretical surface area) for the three gold electrodes real surface area. The chemosorption of tetrakis (benzylmercapto) phthalocyanine (MTBMPc, complexes 1-5a, Fig. 1) and tetrakis (dodecylmercapto) phthalocyanine (MTDMPc, complexes 15b, Fig. 1) complexes of $\mathrm{Mn}^{+3}, \mathrm{Co}^{+2}, \mathrm{Fe}^{+2}, \mathrm{Ni}^{+2}$ and $\mathrm{Zn}^{+2}$ on gold electrodes was achieved by the immersion of gold electrodes in the various solutions containing the complex in DCM. Well established voltammetric methods [29] and [30] were used to investigate the integrity of the SAMs formed on gold electrodes.

An investigation of the minimum time needed for the formation of a stable and well packed SAM was conducted with the use of the cyclic voltammetry curves of $\left[\mathrm{Fe}(\mathrm{CN})_{6}\right]^{-3} /\left[\mathrm{Fe}(\mathrm{CN})_{6}\right]^{-4}$. Figs. $2 \mathrm{a}$ and $\mathrm{b}$ show the typical cyclic voltammograms of $1 \mathrm{mM}$ $\mathrm{K}_{3} \mathrm{Fe}(\mathrm{CN})_{6}$ in $0.2 \mathrm{M} \mathrm{KCl}$ on CoTBMPc-SAM and CoTDMPc-SAM electrodes for different formation times. The cobalt analogues of these MPcs were used for the study because from several repetitive experiments, they were the only analogues found not to inhibit the $\left[\mathrm{Fe}(\mathrm{CN})_{6}\right]^{-3} /\left[\mathrm{Fe}(\mathrm{CN})_{6}\right]^{-4}$ redox reaction (depending on SAM formation time). The lack of inhibition of this redox system has been observed before using adsorbed cobalt tetra-aminophthalocyanine films on vitreous carbon electrodes [31]. It was 
reported [31] that both modified and unmodified electrodes showed the same redox potential and almost equal peak currents intensities for the $\left[\mathrm{Fe}(\mathrm{CN})_{6}\right]^{-3} /\left[\mathrm{Fe}(\mathrm{CN})_{6}\right]^{-4}$ redox reaction, and that the modified electrodes act as electronic conductors which allow rapid electron transfer to the solution species. It was also reported before [32] that among tetraamino phthalocyanine complexes of $\mathrm{Co}^{\mathrm{II}}, \mathrm{Cu}^{\mathrm{II}}$ and $\mathrm{Fe}^{\mathrm{II}}$, only the cobalt analog MPcSAM catalysed the $\left[\mathrm{Fe}(\mathrm{CN})_{6}\right]^{3-} /\left[\mathrm{Fe}(\mathrm{CN})_{6}\right]^{4-}$ redox reaction, this indicate the involvement of centre metal, $\mathrm{Co}^{+2}$ in the catalysis of the redox reaction. Thus, the observed lack of blocking of the $\left[\mathrm{Fe}(\mathrm{CN})_{6}\right]^{-3} /\left[\mathrm{Fe}(\mathrm{CN})_{6}\right]^{-4}$ redox reaction by $\mathrm{CoPc}$ complexes and not by other MPc complexes may be due to the involvement of the $\mathrm{Co}^{+2}$ central ion in the catalysis of the $\left[\mathrm{Fe}(\mathrm{CN})_{6}\right]^{-3} /\left[\mathrm{Fe}(\mathrm{CN})_{6}\right]^{-4}$ redox reaction. A well formed CoPc-SAM in which the molecules have flat orientation on the gold electrodes and the $\mathrm{Co}^{2+}$ is well exposed to the electrolyte solution should not inhibit this redox reaction and it is expected to show similar voltammograms to that of bare gold electrode. The fact that $\left[\mathrm{Fe}(\mathrm{CN})_{6}\right]^{-3} /\left[\mathrm{Fe}(\mathrm{CN})_{6}\right]^{-4}$ current on gold and CoTBMPc-SAM or CoTDMPc-SAM electrodes are identical can be explained by the reversibility of this couple. Catalysis is expected to increase electron transfer rate but for a reversible process it is mass transport that determines the overall reaction rate at all applied potentials, therefore increase in electron transfer rate does not increase the overall rate, resulting in identical curves. A multi-layer or non-flat orientation of the molecules on gold electrodes may cause partial blockage of the central metal ion, $\left(\mathrm{Co}^{+2}\right)$ from getting exposed to the electrolyte solution. For $\mathrm{SAM}_{1}, \mathrm{SAM}_{6}$ and $\mathrm{SAM}_{18}$ (subscripts represent hours of SAM formation, Fig. 2), it can be said that there is no blockage of $\mathrm{Co}^{+2}$ hence no significant decrease in both anodic and cathodic currents compared to that of the bare gold electrode and also no significant shift in the peak potentials while for $\mathrm{SAM}_{24}$ and $\mathrm{SAM}_{48}$ there were decrease in both anodic and cathodic peak currents and also increase in the peak separation $(\Delta E)$. The decrease in peak currents was more pronounced for the CoTDMPc-SAM. The reason for these changes in the $\mathrm{CVs}$ of the $\left[\mathrm{Fe}(\mathrm{CN})_{6}\right]^{-3} /\left[\mathrm{Fe}(\mathrm{CN})_{6}\right]^{-4}$ system at $\mathrm{SAM}_{24}$ and $\mathrm{SAM}_{48}$ could be due to the fact that the remaining gold sites were filled up but not necessary in the flat orientation but vertical orientation in which just one or two of the thiol "arms" were bound to the gold sites and this can cause a partial blocking of the $\mathrm{Co}^{+2}$ ions from getting exposed to the electrolyte solutions. 


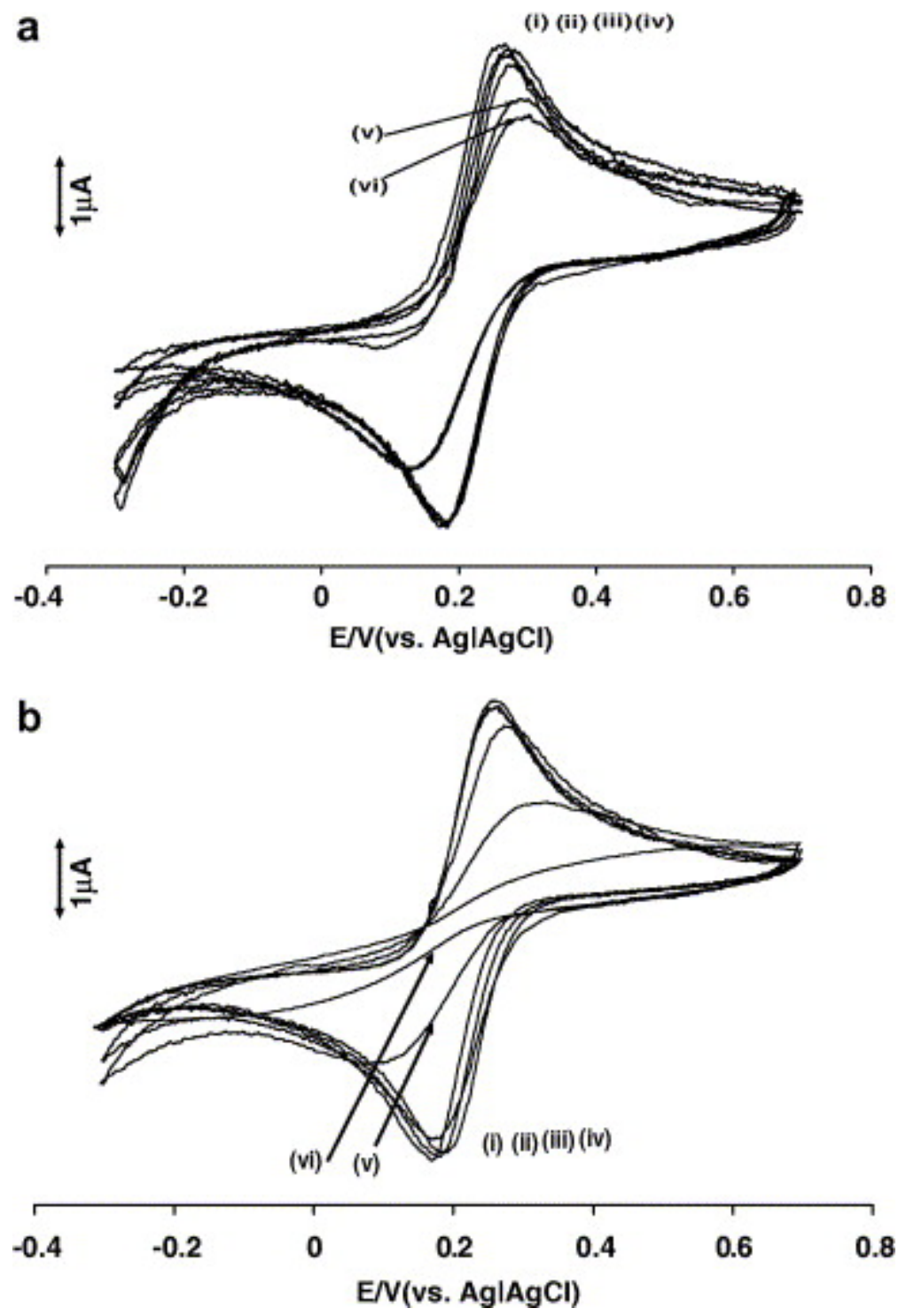

Fig. 2. Typical comparative cyclic voltammograms showing the responses of gold electrodes at different SAM formation time (i) bare gold, (ii) $1 \mathrm{~h}$, (iii) $6 \mathrm{~h}$, (iv) $18 \mathrm{~h}$, (v) $24 \mathrm{~h}$, (vi) $48 \mathrm{~h}$ with (a) CoTBMPc and (b) CoTDMPc. Electrolyte $=1 \mathrm{mM} \mathrm{K}_{3} \mathrm{Fe}(\mathrm{CN})_{6}$ in $0.2 \mathrm{M} \mathrm{KCl}$. Scan rate $=50 \mathrm{mV} / \mathrm{s}$.

\subsection{Blocking characteristics of the faradaic reactions by MPc-SAMs}

The integrity of the different SAM formed at different times were monitored using CVs in $10 \mathrm{mM} \mathrm{KOH}$ (in air), Figs. 3a and b. Peaks I, II and III (curve i) are respectively gold oxidation, gold oxide reduction and oxygen reduction peaks. For all MPc complexes under consideration in this work and for all the SAM formation times, there was blockage 
of both gold surface oxidation and oxygen reduction reactions indicating an effective SAM formation (similar results were obtained for nitrogen saturated $10 \mathrm{mM} \mathrm{KOH}$ aqueous solution, except peak III was absent). The charge difference between the bare gold $\left(Q_{\text {Bare }}\right)$ and the MPc-SAMs $\left(Q_{\mathrm{SAM}}\right)($ Fig. 3$)$ is proportional to the fraction of the gold sites covered by the MPc-SAMs and was employed for the estimation of the complexes' surface concentration on gold electrode.
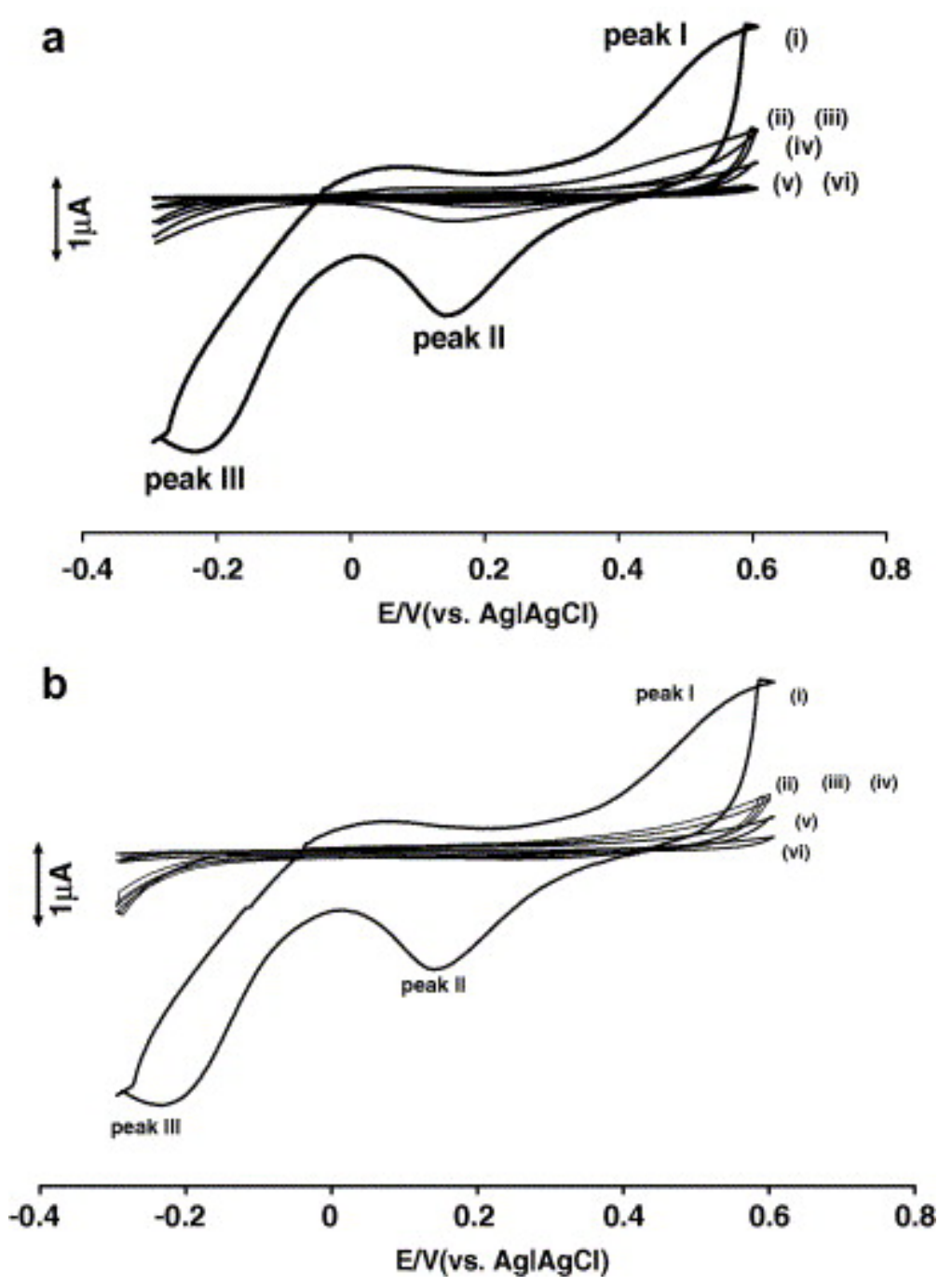

Fig. 3. Typical comparative cyclic voltammograms showing the responses of gold electrode at different SAM formation time (i) bare gold, (ii) $1 \mathrm{~h}$, (iii) $6 \mathrm{~h}$, (iv) $18 \mathrm{~h}$, (v) $24 \mathrm{~h}$, (vi) $48 \mathrm{~h}$ with (a) CoTBMPc and (b) CoTDMPc. Electrolyte $=10 \mathrm{mM} \mathrm{KOH}$. Scan rate $=50 \mathrm{mV} / \mathrm{s}$. 
This fraction is then divided by three to get the charge proportion of gold sites covered with MPc-SAM, according to the following equation [33].

$$
\mathrm{Au} \cdot \mathrm{H}_{2} \mathrm{O}+2 \mathrm{H}_{2} \mathrm{O} \equiv \mathrm{Au}(\mathrm{OH})_{3}+3 \mathrm{H}^{+}+3 \mathrm{e}^{-}
$$

The amount of gold sites covered by the MPc-SAM is then divided by four (each MPc molecule is assumed to consume four gold sites since the complexes are tetra substituted with thiol groups) and then divided by $0.0201 \mathrm{~cm}^{2}$ which is the geometric area of the gold electrode surface to get the charge density proportional to each MPc molecule. These values can then be converted to the corresponding surface concentration $\left(\Gamma_{\mathrm{MPc}}, \mathrm{mol} / \mathrm{cm}^{2}\right)$ by dividing them with the Faraday constant $\left(96485 \mathrm{C} \mathrm{mol}^{-1}\right)$. The surface concentration in number of molecules per area (in $\mathrm{cm}^{2}$ ) can be obtained by simply multiplying the $\Gamma_{\mathrm{MPc}}$ $\left(\mathrm{mol} / \mathrm{cm}^{2}\right)$ by the Avogadro's constant $\left(N_{\mathrm{A}}\right)$. Finally the inverse of the concentration in molecules per $\AA^{2}$ corresponds to the approximate surface area occupied per molecule. Table 1 shows the various approximate surface concentration values in $\mathrm{mol} / \mathrm{cm}^{2}$ and the corresponding approximate gold surface area occupied per molecule $\left(\AA^{2}\right)$ for various SAMs formed at different times, using CoTBMPc and CoTDMPc as examples. For both CoTBMPc and CoTDMPc complexes, $\mathrm{SAM}_{1}$ and $\mathrm{SAM}_{6}$ have a significantly less surface concentration compared to the $\sim 10^{-10} \mathrm{~mol} / \mathrm{cm}^{2}$ value for monolayers while $\mathrm{SAM}_{18}$ concentration values for both complexes are within the monolayer concentration range. Both complexes, $\mathrm{SAM}_{24}$ and $\mathrm{SAM}_{48}$ showed higher surface concentration values than that of $\mathrm{SAM}_{18}$, as stated before, this may probably be due to the filling up of the remaining gold sites not necessary in the octopus orientation but vertical orientation in which there will be one or two of the thiol 'arms' involved in the binding to the gold sites. 
Table 1.

Comparative surface concentration and approximate gold surface area occupied per molecule $\left(\AA^{2}\right)$ for the CoPcs-SAMs formed at different times

\begin{tabular}{|c|c|c|}
\hline $\begin{array}{l}\text { Time } \\
\text { (h) }\end{array}$ & $\begin{array}{l}\text { CoTBMPc surface concentration } \\
\left(10^{10} \mathrm{~mol} \mathrm{~cm}^{-2}\right)\end{array}$ & $\begin{array}{l}\text { CoTDMPc surface concentration } \\
\left(10^{10} \mathrm{~mol} \mathrm{~cm}^{-2}\right)\end{array}$ \\
\hline 1 & $0.40(415)$ & $0.42(396)$ \\
\hline 6 & $0.64(260)$ & $0.69(243)$ \\
\hline 18 & $0.82(203)$ & 0.87 (191) \\
\hline 24 & $1.12(148)$ & $1.30(127)$ \\
\hline 48 & $1.31(126)$ & $1.42(117)$ \\
\hline
\end{tabular}

Numbers in brackets represent the approximate gold surface area occupied per molecule $\left(\AA^{2}\right)$.

The surface concentration value of the SAM formed by the MTDMPc is larger than the MTBMPc counterparts, (see Table 1 for CoPc complexes at different formation times and Table 2 for all complexes at $18 \mathrm{~h}$ formation time). Also from Figs. $2 \mathrm{a}$ and $\mathrm{b}$ there was more inhibition of $\left[\mathrm{Fe}(\mathrm{CN})_{6}\right]^{-3} /\left[\mathrm{Fe}(\mathrm{CN})_{6}\right]^{-4}$ redox process (as judged by less anodic and cathodic peak currents and higher $\Delta E \mathrm{~s}$ ) for the CoTDMPc SAM than their CoTDMPc counterparts for both $\mathrm{SAM}_{24}$ and $\mathrm{SAM}_{48}$, the influence of the ring substituents could be responsible for these observations. Long chain alkanethiols are known to form closely packed SAM on gold electrodes and in addition, the $\mathrm{C}_{12}$ alkyl chain could cause more blocking of $\mathrm{Co}(\mathrm{II})$ than the benzylmercapto groups of the CoTBMPc. 
Table 2 .

Comparative surface concentration and approximate gold surface area occupied per molecule $\left(\AA^{2}\right)$ for the various MPcs-SAMs

\begin{tabular}{|l|l|}
\hline MPc complex & \left. Surface concentration ${\mathbf{~} 10^{\mathbf{1 0}} \mathbf{~ m o l ~ c m}}^{-2}\right)$ \\
\hline CoTBMPc & $0.82(203)$ \\
\hline CoTDMPc & $0.87(191)$ \\
\hline FeTBMPc & $0.70(235)$ \\
\hline FeTDMPc & $0.74(224)$ \\
\hline MnTBMPc & $0.66(253)$ \\
\hline MnTDMPc & $0.74(224)$ \\
\hline NiTBMPc & $0.83(201)$ \\
\hline NiTDMPc & $0.88(189)$ \\
\hline ZnTBMPc & $0.75(221)$ \\
\hline ZnTDMPc & $0.78(212)$ \\
\hline
\end{tabular}

SAM formation time $=18 \mathrm{~h}$. Numbers in brackets represent the approximate gold surface area occupied per molecule $\left(\AA^{2}\right)$.

A good way of measuring how well SAM has isolated the gold electrode from the electrolyte solution is the so called ion barrier factor, $\Gamma_{\mathrm{ibf}}$ which can be obtained by:

$$
\Gamma_{\mathrm{ibf}}=1-Q_{\mathrm{SAM}} / Q_{\mathrm{Bare}}
$$

where $Q_{\text {Bare }}$ and $Q_{\mathrm{SAM}}$ are the total charges produced under the peak due to the reduction at the bare and at SAM modified gold electrodes, (Fig. 3). The $\Gamma_{\text {ibf }}$ values (calculated at $18 \mathrm{~h}$ deposition time) were close to unity for all complexes, and this implies that the SAMs are effective in providing barriers to ion and solvent permeability.

The minimum time required for a closely packed SAM to be formed based on the series of characterisation above can be estimated as $18 \mathrm{~h}$ from the discussion above. This time was then used for the formation of SAMs of the other eight complexes. Table 2 shows the SAM parameters, approximate surface concentration $\left(\mathrm{mol} / \mathrm{cm}^{2}\right)$ and corresponding approximate gold surface area occupied per molecule $\left(\AA^{2}\right)$ for all the SAMs formed by 
the complexes after $18 \mathrm{~h}$. It is very clear that for all the complexes, well packed SAMs were formed with the values of surface concentrations within the monolayer values in which the molecules are lying in octopus configuration on the gold electrode surface and occupying approximately $200 \AA^{2}$ per molecule.

To further check the integrity of MPc-SAMs formed on gold electrode, their blocking behaviour towards Faradaic processes; redox chemistry of $1 \times 10^{-3} \mathrm{M} \mathrm{Fe}\left(\mathrm{NH}_{4}\right)\left(\mathrm{SO}_{4}\right)_{2}$ in $1 \mathrm{M} \mathrm{HClO}_{4}$ and under potential deposition (UPD) of $\mathrm{Cu}$ in $0.5 \mathrm{M} \mathrm{H}_{2} \mathrm{SO}_{4}$ were investigated. Fig. 4 shows the $\mathrm{CV}$ of $\mathrm{Fe}\left(\mathrm{NH}_{4}\right)\left(\mathrm{SO}_{4}\right)_{2}$ in $1 \times 10^{-3} \mathrm{M} \mathrm{HClO}_{4}$ on bare gold (curve i) and that of the CoTBMPc-SAM (curve ii) and CoTDMPc-SAM (curve iii) modified electrodes, it is clear that the quasi reversible redox reaction $\left[\mathrm{Fe}\left(\mathrm{H}_{2} \mathrm{O}\right)_{6}\right]^{+3} /\left[\mathrm{Fe}\left(\mathrm{H}_{2} \mathrm{O}\right)_{6}\right]^{+2}$ which occurred at the bare gold electrode is inhibited at the CoPcs-SAM modified gold electrodes. This is a good indication that the SAM formed are well packed and effectively isolate the gold surface from the electrolyte solution. Fig. 5 shows the typical voltamogramms of a $1 \times 10^{-3} \mathrm{M} \mathrm{CuSO}_{4}$ in $0.5 \mathrm{M} \mathrm{H}_{2} \mathrm{SO}_{4}$ on bare gold electrode, CoTBMPc-SAM and CoTDMPc-SAM modified electrodes. It has been shown [20] that metal deposition involve both bulk deposition of the metal at potentials close to the thermodynamic potential and UPD at potentials well positive of the thermodynamic potential. This method has been previously used by our group [34] and [35] to characterise MPc-SAM gold electrodes. The UDP of $\mathrm{Cu}$ and the stripping peaks occurred at about -0.2 and $+0.1 \mathrm{~V}$ respectively at the bare gold electrode as shown in Fig. 5 . These peaks did not appear in the CVs obtained at CoPcs-SAM gold electrodes clearly showing that the CoPcs-SAMs formed are well packed and almost free from pinholes and defects. Similar results in both experiments were also obtained for the other MPcs-SAM electrodes. 


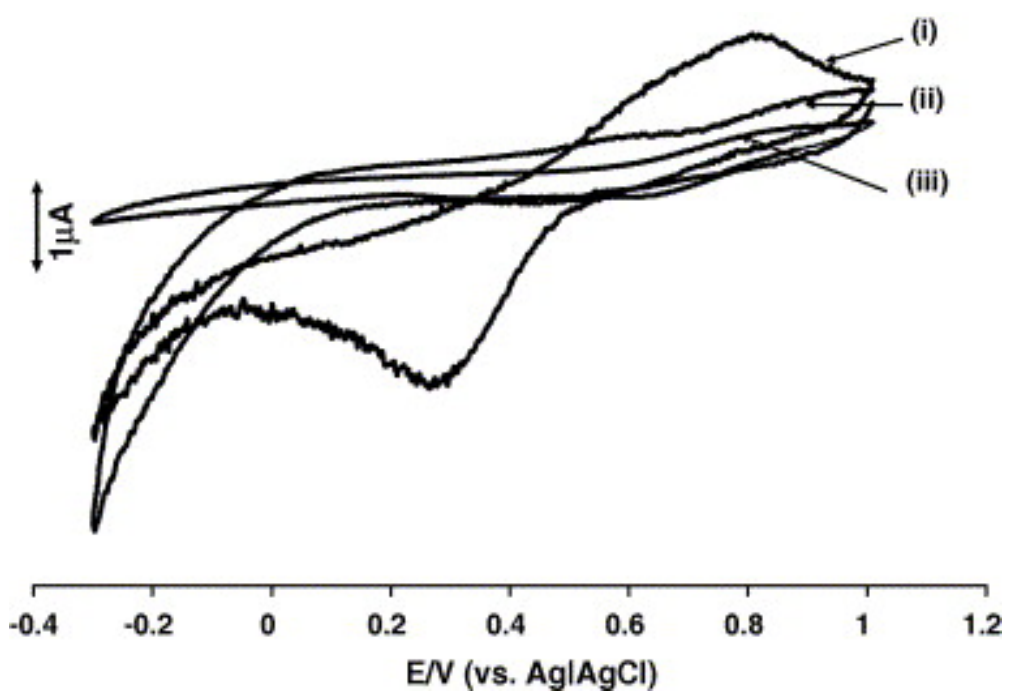

Fig. 4. Typical cyclic voltammograms of $1 \mathrm{mM} \mathrm{Fe}\left(\mathrm{NH}_{4}\right)\left(\mathrm{SO}_{4}\right)_{2}$ in $1 \mathrm{mM} \mathrm{HClO}_{4}$ electrolyte at: (i) bare gold electrode, (ii) CoTBMPc-SAM gold electrode, (iii) CoTDMPc-SAM gold electrode. Scan rate $=50 \mathrm{mV} / \mathrm{s}$.
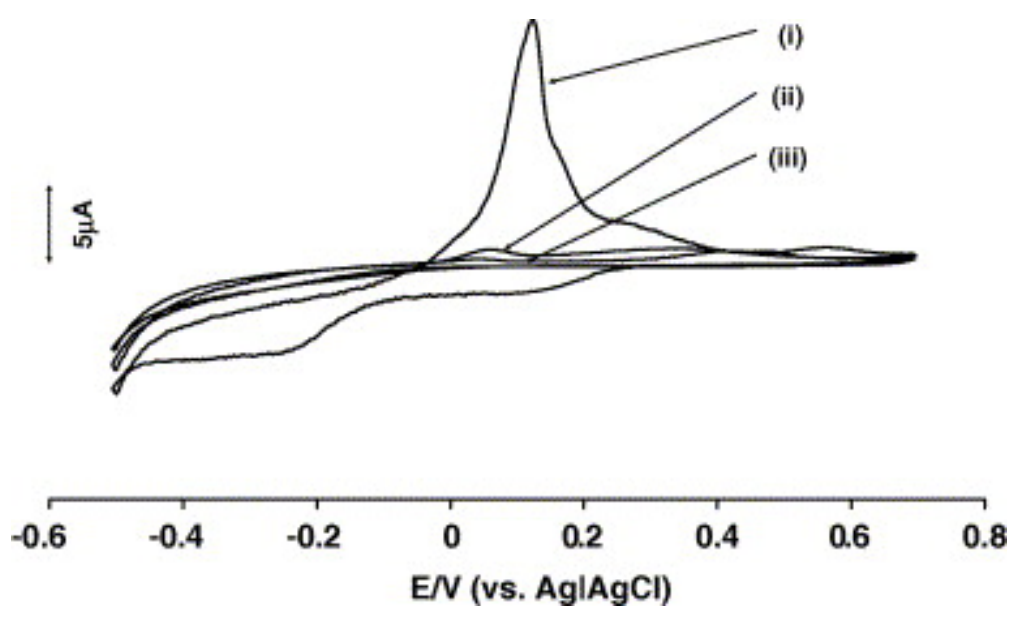

Fig. 5. Typical cyclic voltammograms of UPD of $1 \mathrm{mM} \mathrm{CuSO}_{4}$ in $0.5 \mathrm{M} \mathrm{H}_{2} \mathrm{SO}_{4}$ electrolyte at (i) bare gold electrode, (ii) CoTBMPc-SAM gold electrode, (iii) CoTDMPc-SAM gold electrode. Scan rate $=50 \mathrm{mV} / \mathrm{s}$.

\subsection{Central metal oxidation couples of the MPc-SAM electrodes}

It is important to identify the redox couples of the central metal of the immobilised MPcs on gold as this will be needed in their applications as electrocatalysts and sensors. Ill defined cyclic voltammograms are often obtained for these redox processes [24] and [34] (especially oxidation processes) and often activation is needed in order to see well 
defined CVs. Fig. 6 shows the CVs obtained at bare gold (curve i), CoTBMPc-SAM gold (curve ii) and CoTDMPc-SAM gold (curve iii) electrodes after activation of the modified electrodes by repetitive cycling in phosphate buffer $\mathrm{pH} 4$. For both complexes, the anodic peak current increased linearly with the scan rate indicating Faradaic reactions of a surface confined species (Fig. 6, inset). The $\Delta E$ values for both couples are 170 and $180 \mathrm{mV}$ respectively. Table 3 gives the details of the $E_{\mathrm{pa}} / E_{\mathrm{pc}}$ values for the central metal ion redox processes, as expected, both ZnTBMPc and ZnTDMPc complexes did not show central metal ion redox processes since $\mathrm{Zn}(\mathrm{II})$ is not electroactive, NiTBMPc and NiTDMPc complexes also behaved the same way, showing no $\mathrm{Ni}$ (III)/Ni(II) redox processes; nickel phthalocyanine complexes are known to show redox processes only on the ring [36] unless activated in strong alkaline solutions.

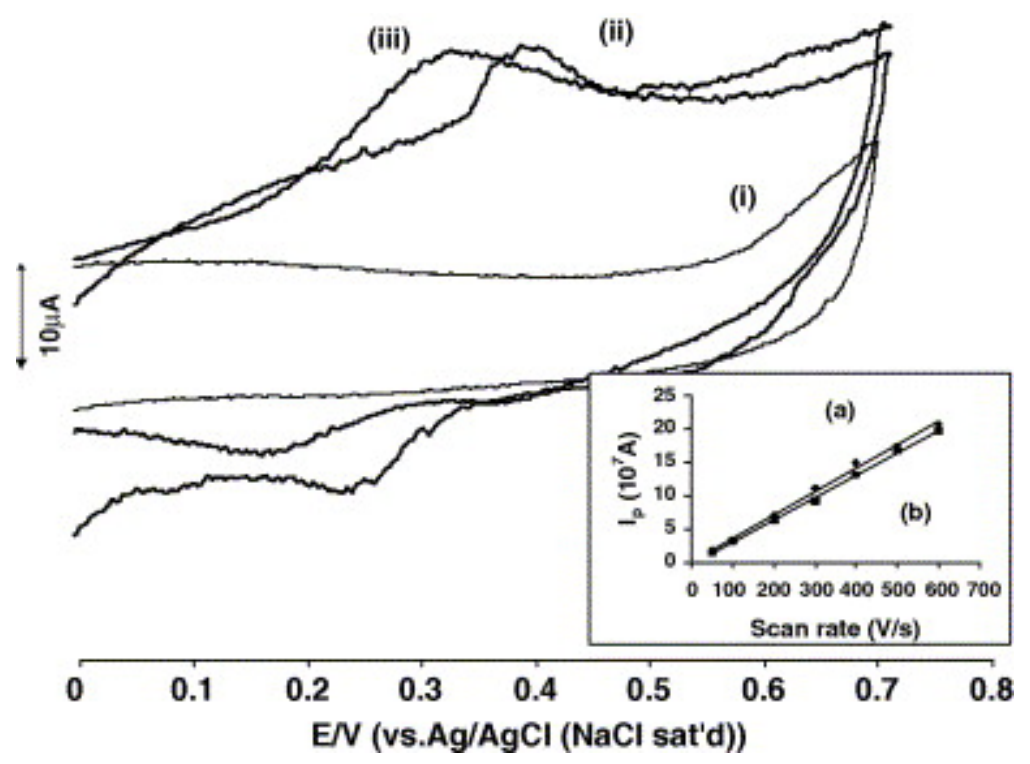

Fig. 6. Comparative cyclic voltammograms obtained at (i) bare gold electrode, (ii) CoTBMPc-SAM gold electrode and (iii) CoTDMPc-SAM gold electrode in phosphate buffer $\mathrm{pH}$ 4. Inset is the plot of anodic peak currents (a) CoTBMPc and (b) CoTDMPc versus scan rate. Scan rate $=100 \mathrm{mV} / \mathrm{s}$. 
Table 3 .

Comparative $E_{\mathrm{pa}} / E_{\mathrm{pc}}(\mathrm{V})$ for the metal based redox couple reactions of the immobilised MPcs on gold electrodes

\begin{tabular}{|l|l|}
\hline MPc complex & $\boldsymbol{E}_{\mathbf{1} / \mathbf{2}}(\mathbf{V})$ \\
\hline CoTBMPc & $0.32\left(\mathrm{Co}^{+3} / \mathrm{Co}^{+2}\right)$ \\
\hline CoTDMPc & $0.24\left(\mathrm{Co}^{+3} / \mathrm{Co}^{+2}\right)$ \\
\hline FeTBMPc & $0.39\left(\mathrm{Fe}^{+3} / \mathrm{Fe}^{+2}\right)$ \\
\hline FeTDMPc & $0.37\left(\mathrm{Fe}^{+3} / \mathrm{Fe}^{+2}\right)$ \\
\hline MnTBMPc & $0.27\left(\mathrm{Mn}^{+4} / \mathrm{Mn}^{+3}\right)$ \\
\hline MnTDMPc & $0.17\left(\mathrm{Mn}^{+4} / \mathrm{Mn}^{+3}\right)$ \\
\hline NiTBMPc & None \\
\hline NiTDMPc & None \\
\hline ZnTBMPc & None \\
\hline ZnTDMPc & None \\
\hline
\end{tabular}

\subsection{Stability of MPc-SAMs}

The stability of the MPcs-SAM was also studied, this was studied as a function of $\mathrm{pH}$ and applied potential. The immobilised films showed high stability from $\mathrm{pH} 2$ to 9 in the potential window -0.2 to $+0.8 \mathrm{~V}$ However, at $\mathrm{pH}>9$ and at potential outside this window resulted to the SAM desorption. These thiol derivatised metallophthalocyanine complexes SAM modified gold electrodes showed stability with no detectable desorption when they were stored for over a period of one month in both $\mathrm{pH} 4$ and $\mathrm{pH} 7$ phosphate buffers.

\section{Conclusion}

This works shows that benzyl- and dodecyl-mercapto tetra substituted first transition metal phthalocyanines complexes on gold electrodes formation of stable, well packed and defect free SAMs. Using the $\mathrm{Fe}(\mathrm{CN})^{-3} / \mathrm{Fe}(\mathrm{CN})_{6}^{-4}$ redox system as a guide, it was 
shown that a possible change in molecules orientation from flat to vertical with increase in SAM formation time to values greater than $18 \mathrm{~h}$. Ring substituents influenced the blocking characteristics of the CoPcs-SAM towards $\left[\mathrm{Fe}(\mathrm{CN})_{6}\right]^{-3} /\left[\mathrm{Fe}(\mathrm{CN})_{6}\right]^{-4}$ redox process, MTDMPc with dodecylmercapto ring substituents showing more blocking characteristic than that of MTBMPc with benzylmercapto ring substituents. The electrochemical application of these MPcs-SAMs is limited to a potential window -0.2 to $+0.8 \mathrm{~V}$ vs. $\mathrm{Ag} \mid \mathrm{AgCl}(\mathrm{NaCl}$, sat'd) preferably in acidic and neutral $\mathrm{pH}$. Potential applications of these SAMs as electrochemical sensors for environmentally important molecules are being studied in our laboratories.

\section{References}

[1] D. Worhle and D. Meissener, Adv. Mater. 3 (1991), p. 129.

[2] D. Worhle, L. Kreienhoop and D. Schlettwein In: A.P.B. Lever and C.C. Leznoff, Editors, Phthalocyanine: Properties and Applications vol. 4, VCH Publishers, New York (1996).

[3] B. Simic-Glavaski In: A.P.B. Lever and C.C. Leznoff, Editors, Phthalocyanine: Properties and Applications vol. 3, VCH Publishers, New York (1993).

[4] K. Hanabusa and H. Shirai In: A.P.B. Lever and C.C. Leznoff, Editors, Phthalocyanine: Properties and Applications vol. 2, VCH Publishers, New York (1993). [5] H. Kasaga In: A.P.B. Lever and C.C. Leznoff, Editors, Phthalocyanine: Properties and Applications vol. 4, VCH Publishers, New York (1996).

[6] B. Meunier and A. Sorokin, Acc. Chem. Res. 30 (1997), p. 470.

[7] B. Agboola, K.I. Ozoemena and T. Nyokong, J. Mol. Cat. A 227 (2005), p. 209.

[8] A.W. Snow and W.R. Barger In: A.P.B. Lever and C.C. Leznoff, Editors,

Phthalocyanine: Properties and Application vol. 1, VCH Publishers, New York (1989).

[9] J. Obirai and T. Nyokong, Electrochim. Acta 49 (2004), p. 1417.

[10] F. Bedioui, Y. Bouhier, C. Sorel, J. Devynck, L. Coche-Guerente, A. Deronzier and J.C. Montet, Electrochim. Acta 38 (1993), p. 2485.

[11] A.J. Downard, Electroanalysis 12 (2000), p. 1085.

[12] I. Zilbermann, J. Hayon, T. Katchalski, R. Ydgar, J. Rishpon, A.I. Shames, E. Korin and A. Bettlelheim, Inorg. Chim. Acta 305 (2000), p. 53. 
[13] C.A. Caro, F. Bedioui and J.H. Zagal, Electrochim. Acta 47 (2002), p. 1489.

[14] P.S. Vukusic and J.R. Sambles, Thin Solid Films 221 (1992), p. 311.

[15] M.J. Cook, J. Mater. Chem. 6 (1996), p. 677.

[16] M.J. Cook, D.A. Mayes and R.H. Poynter, J. Mater. Chem. 5 (1995), p. 2233.

[17] B.M. Hassan, H. Li and N.B. Mckeown, J.Mater. Chem. 10 (2000), p. 39.

[18] M.J. Cook, Pure Appl. Chem. 71 (1999), p. 2145.

[19] A. Ulman, An Introduction to Ultrathin Organic Films: From Langmuir-Blodgett to Self-assembly, Academic Press, San Diego (1991).

[20] H.O. Finklea In: A.J. Bard and I. Rubinstein, Editors, Electroanalytical Chemistry vol. 19, Marcel Dekker, New York (1996), p. 109.

[21] H.O. Finklea In: R.A. Meyers, Editor, Encyclopaedia of Analytical Chemistry:

Applications Theory and Instrumentations vol. 11, Wiley, Chichester (2000), p. 10090.

[22] Z. Li and M. Liberman In: J.P. Blitz and C.B. Little, Editors, Fundamental and Applied Aspects of Chemically Modified Surfaces, Royal Society of Chemistry (1999), pp. 24-35.

[23] Z. Li, M. Lieberman and W. Hill, Langmuir 17 (2001), p. 4887.

[24] K. Ozoemena, P. Westbroek and T. Nyokong, Electrochem. Commun. 3 (2001), p. 529.

[25] C.D. Bain, E.B. Troughton, Y.-T. Tao, J. Evall, G.M. Whitesides and R.G. Nuzzo, J. Am. Chem. Soc. 111 (1989), p. 321.

[26] D.J. Revell, I. Chambrier, M.J. Cook and D.A. Russell, J. Mater. Chem. 10 (2000), p. 31.

[27] B. Agboola, K.I. Ozoemena and T. Nyokong, Electrochim. Acta 51 (2006), p. 4379.

[29] D. Losic, J.G. Shapter and J.J. Gooding, Langmuir 17 (2001), p. 3307.

[30] E. Sabatani and I. Rubinstein, J. Phys. Chem. A 91 (1987), p. 6663.

[31] S. Griveau, J. Pavez, J.H. Zagal and F. Bedioui, J. Electroanal. Chem. 497 (2001), p. 75.

[32] M.P. Somashekarappa, J. Keshavayya and S. Sampath, Pure Appl. Chem. 74 (2002), p. 1609.

[33] K. Juodkazis, J. Juodkazyte, B. Sebeka and A. Lukinskas, Electrochem. Commun. 1 (2001), p. 315. 
[34] K.I. Ozoemena, T. Nyokong and P. Westbroek, Electroanalysis 14 (2003), p. 1762. [35] K. Ozoemena, P. Westbroek and T. Nyokong, J. Porphyr. Phthalocya. 6 (2002), p. 98.

[36] A.B.P. Lever, E.L. Milaeva and G. Speier In: C.C. Leznoff and A.B.P. Lever, Editors, Phthalocyanines. Properties and Applications vol. 3, VCH Publishers, New York (1993), pp. 1-69 (Chapter 1).

Corresponding author. Tel.: +32 92645407; fax: +3292645846. 